\title{
Palliative gastrectomy plus chemotherapy versus chemotherapy alone for incurable advanced gastric cancer: a meta-analysis
}

This article was published in the following Dove Press journal:

Cancer Management and Research

\author{
Pei Wu' \\ Pengliang Wang' \\ Bin $\mathrm{Ma}^{2}$ \\ Songcheng Yin' \\ Yuen Tan' \\ Wenbin Hou' \\ Zhenning Wang' \\ Huimian $\mathrm{Xu}^{\prime}$ \\ Zhi Zhu' \\ 'Department of Surgical Oncology, \\ First Affiliated Hospital of China \\ Medical University, Shenyang II000I, \\ China; ${ }^{2}$ Department of Colorectal \\ Surgery, Cancer Hospital of China \\ Medical University, Liaoning Cancer \\ Hospital and Institute, Dadong \\ District, Shenyang I I0042, Liaoning \\ Province, China
}

Correspondence: Zhi Zhu

Department of Surgical Oncology, First Affiliated Hospital of China Medical University, North Nanjing Street 155, Shenyang I I000I, China

Tel +862483283556

Fax +862483283556

Email zhuzhi@yeah.net
Background: Whether palliative gastrectomy combined with chemotherapy can improve the survival of patients with advanced gastric cancer remains controversial. We performed a metaanalysis to clarify whether palliative gastrectomy plus chemotherapy can benefit patients with incurable advanced gastric cancer and to explore the best candidates in this patient population. Methods: We searched the literature systematically using electronic databases including PubMed, EMBASE, and the Cochrane Library. And HRs and their 95\% CIs were used to express the results for overall survival (OS) and progression-free survival (PFS).

Results: One randomized controlled trial with 175 patients and 12 cohort studies with 2,193 patients were analyzed. The pooled HR for OS (HR=0.43, 95\% CI $=0.29-0.65, P<0.001)$, subgroup analysis of stage $\mathrm{M} 1(\mathrm{HR}=0.53,95 \% \mathrm{CI}=0.40-0.72, P<0.001)$, peritoneal dissemination $(\mathrm{HR}=0.46,95 \% \mathrm{CI}=0.28-0.73, P=0.001)$, and liver metastasis $(\mathrm{HR}=0.46,95 \% \mathrm{CI}=0.33-0.65$, $P<0.001)$ all indicated the superiority of palliative gastrectomy plus chemotherapy. However, the pooled HR for PFS (HR=0.61, 95\% $\mathrm{CI}=0.33-1.13, P=0.110)$ got separate outcome.

Conclusion: The results of this meta-analysis indicated that palliative gastrectomy plus chemotherapy can improve OS for incurable advanced gastric cancer. In addition, analyses based on liver metastasis and peritoneal dissemination demonstrated the advantages of palliative gastrectomy plus chemotherapy. However, the PFS of incurable advanced gastric cancer with palliative gastrectomy plus chemotherapy was no better than that under chemotherapy alone.

Keywords: advanced gastric cancer, palliative gastrectomy, chemotherapy, survival

\section{Introduction}

Advanced gastric cancer is a common and fatal disease, and it is still the second leading cause of cancer-related deaths worldwide despite decline in its incidence and mortality in recent years. ${ }^{1}$ In patients with stages III and IV gastric cancer, the 5-year overall survival (OS) rates are only $9.2 \%-19.8 \%$ and $4.0 \%$, respectively. Furthermore, most patients with gastric cancer are diagnosed at the advanced stage because cancer usually remains asymptomatic or nonspecific symptoms are present. ${ }^{2,3}$ The third Japanese Gastric Cancer Association (JGCA) treatment guidelines and the 2013 National Comprehensive Cancer Network recommendations for gastric cancer state that chemotherapy is the main treatment modality for stage IV gastric cancer. ${ }^{4,5}$ In addition, the JGCA guidelines suggest that stage IV patients without major symptoms could be treated with gastrectomy as an alternative option. ${ }^{6}$ Therefore, we hypothesize that palliative gastrectomy combined with chemotherapy might increase the survival of patients with advanced gastric cancer. 
It is still unclear whether surgical resection is a suitable treatment for incurable advanced gastric cancer. In recent years, the REGATTA clinical trial concluded that surgical resection does not provide any greater benefit for incurable advanced gastric cancer compared with palliative chemotherapy. ${ }^{7,16}$ Moreover, some cohort studies have reported the positive effects of palliative gastrectomy combined with chemotherapy on gastric cancer with incurable factors. In the present study, in order to obtain the highest level of evidence by meta-analysis, we merged all the results from trials to find useful evidence regarding clinical treatment and subsequent research. We also analyzed whether palliative gastrectomy combined with chemotherapy has more benefits than chemotherapy alone for incurable advanced gastric cancer in terms of race, site of metastasis, staging, and other variables.

Previously, only one randomized controlled trial (RCT) obtained results that were not consistent with most other studies, thereby providing insufficient evidence. Thus, it is necessary to perform a meta-analysis that includes observed studies that could increase precision appropriately and may produce equally or more relevant and valid results for the question. ${ }^{8}$ Compared with a previous similar meta-analysis that explored the effects of palliative gastrectomy, ${ }^{37}$ our meta-analysis was more rigorous in terms of the inclusion conditions, where all the patients included received chemotherapy, and thus the results are more credible, and the end points were progression-free survival (PFS; the time from random assignment to objective tumor progression or death) and OS (the time from random assignment to the last followup or death), thereby providing a more useful reference for clinical treatment.

\section{Methods}

\section{Literature search}

Studies were mainly searched for in Embase, PubMed, and Cochrane Library, where we considered those published before December 2017, and the keywords were stomach neoplasms, drug therapy, surgical procedures, and operative and neoplasm metastasis. The search strategy was based on medical subject headings and free text words in titles/ abstracts, with connectives comprising "AND" or "OR." We used this search strategy in Embase, PubMed, and the Cochrane Library, and the specific search strategy was adjusted according to the characteristics of each database. Furthermore, we reviewed relevant articles and abstracts in the reference lists from these sources to identify additional trials. The most recent publication was used if results were reported or updated in more than one publication. There were no language restrictions.

\section{Inclusion and exclusion criteria}

After histological or cytological diagnosis, only primary incurable advanced gastric cancer with or without synchronous distant metastasis was included. The definition of incurable advanced gastric cancer is based on the TNM stage as T4N1-3M0, T1-4N3M0 and any T or N with an M1 tumor or gastric cancer with any incurable factors. ${ }^{9,10}$ In addition, metastatic gastric cancer without specific TNM staging still met the conditions for inclusion. All the patients included in the present study received chemotherapy, but only experimental patients received palliative gastrectomy. Because serious symptoms such as hemorrhage, fistula, or ileus may result in high mortality for patients with incurable advanced gastric cancer, specific operation procedure of palliative gastrectomy is performed to alleviate the symptoms and improve the survival quality, depending on the resectability of the primary tumor and/or surgical risk. Therefore, no matter what the extent of gastric resection and/or lymphadenectomy, metastasectomy was excluded. Palliative gastrojejunostomy and reduction gastrectomy were involved in the study, all met the inclusion criteria and would be regarded as palliative gastrectomy. ${ }^{11}$ The sample sizes in all the studies considered were $>30$, and we required that the median survival (OS or PFS) and its HR or survival curve were reported. If necessary, we included any useful supplemental data. We only included studies published in peer-reviewed journals and the latest studies or those with the largest data set. A study was excluded if the required data could not be obtained from the article or the authors.

\section{Data extraction and quality assessment}

The outcome data were extracted independently by two authors (ZZ and PW) according to a predesigned data extraction form, which included the study, year of publication, race, sample size, and treatment effects (median OS/PFS, HR values with 95\% CIs, tumor stage, and distant metastasis). The corresponding study was represented using the last name of the first author. If there were inconsistencies between the opinions of the two authors, a group discussion was conducted.

We used different methods to assess the risk of bias and quality of RCTs and observational studies. According to the guidelines given by the Cochrane Collaboration, the risk of bias and quality of RCTs were assessed comprehensively 
using six items that are considered relevant. The quality level of the study was assessed based on the number of positive answers (high quality $=6$, low quality $\leq 3$, fair quality $=4$ or 5 ) ${ }^{12}$ The risk of bias for observational studies was assessed using the Newcastle-Ottawa Scale (NOS), which is one of the most useful methods for assessing the quality of nonrandomized studies according to the Cochrane Handbook. We used a "star" to evaluate "high" quality for each choice among the "selection," "comparability," and "outcome" items. ${ }^{13}$

\section{Statistical analysis}

The HR and 95\% CI comprise a suitable measure for OS and PFS. If the HR was not provided for OS or PFS in an article, we used Engauge Digitizer 4.1 to distinguish the survival curve, before calculating the HRs for OS or PFS with the method described by Tierney et al. ${ }^{14}$ The $Q$ statistic with its $P$-value and the $I^{2}$ statistic were used to assess the heterogeneity of the study, where the proportion of total variation in the effect estimate due to between-study variation was quantified with the $I^{2}$ statistic. A $Q$ statistic $P$-value $<0.05$ and $I^{2}>50 \%$ were used as critical values for assessing substantial heterogeneity, and a random effects model was then used. ${ }^{15}$ Review Manager version 5.3.0 (The Cochrane Collaboration, Software Update, Oxford, UK) and Stata version 14.0 (StataCorp, College Station, TX, USA) were used, and $P<0.05$ was set as the significance level. If the heterogeneity was significant, we conducted sensitivity and subgroup analyses based on the characteristics in trial, ie, race, $M$ stage, type of study, and site of distant metastasis. Funnel plots were used to assess publication bias, which was quantified using Egger's linear regression test and Begg's rank correlation test.

\section{Results \\ Study selection and characteristics of included studies}

The flow of the trial selection process is shown in Figure 1. Briefly, we searched 5,609 studies using the established search strategy. Finally, we included 13 trials with 2,368 gastric cancer patients after screening the abstracts and full texts, where the palliative gastrectomy plus chemotherapy group comprised 1,166 patients and the chemotherapy alone group

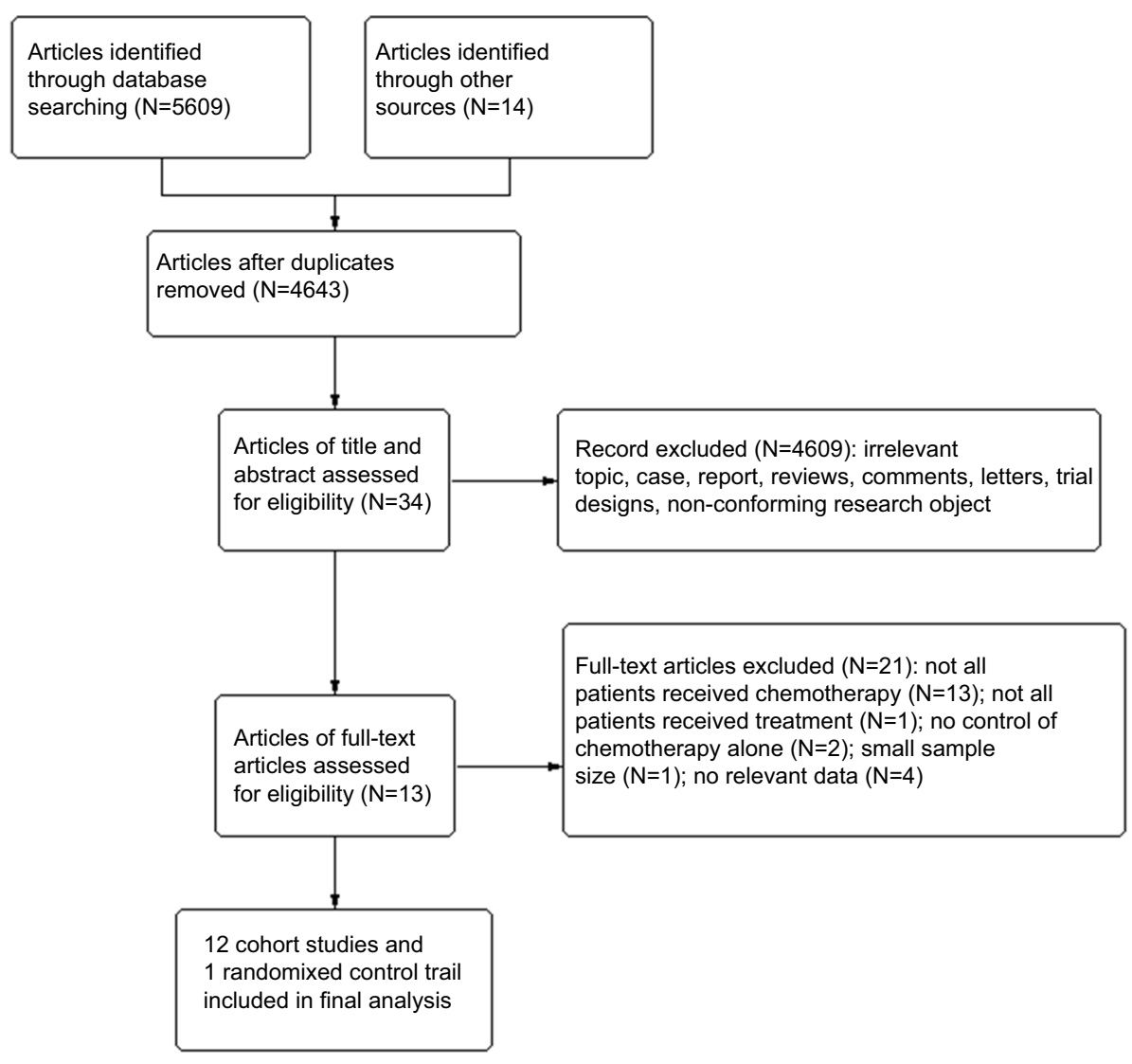

Figure I Flow diagram of the identification process for eligible studies. 
contained 1,141 patients. The characteristics of the 13 trials are shown in Table 1 . We included one RCT and 12 cohort studies that all appeared in peer-reviewed journals between 2011 and 2017. In terms of race, most of the patients in the studies were Asians, including 12 trials, and the patients in the other two trials were Caucasians.

\section{Quality of the studies}

Due to a lack of double-blinding for treatment assignment, five of the six questions had positive answers, which indicated fair quality. In general, the risk bias was acceptable in the important domains. ${ }^{12}$ According to evaluations based on
NOS, the studies considered received 4-7 stars, with median to high methodological quality. Specific assessments of all trials are shown in Table 2.

\section{OS and PFS}

The HRs and 95\% CIs for OS could be determined directly ${ }^{7,16-18}$ or indirectly ${ }^{19-27}$ from 13 studies. Nearly, all the studies supported palliative gastrectomy combined with chemotherapy, but only two obtained separated results ${ }^{16,18}$ when we combined all the HRs for OS in the selected trials, and the results showed that the treatment effect was statistically significant $(\mathrm{HR}=0.43,95 \% \mathrm{CI}=0.29-0.65, P<0.001$, Figure 2$)$,

Table I Study, patient, and treatment characteristics

\begin{tabular}{|c|c|c|c|c|c|c|c|c|c|c|c|c|}
\hline \multirow[t]{2}{*}{ Study } & \multirow[t]{2}{*}{ Year } & \multirow[t]{2}{*}{ Race } & \multirow[t]{2}{*}{ Metastasis } & \multirow[t]{2}{*}{ Patients } & \multicolumn{3}{|c|}{ Research } & \multicolumn{3}{|c|}{ Control } & \multirow{2}{*}{$\begin{array}{l}\text { OS } \\
\text { HR }(95 \% \mathrm{Cl})\end{array}$} & \multirow{2}{*}{$\begin{array}{l}\text { PFS } \\
\text { HR (95\% Cl) }\end{array}$} \\
\hline & & & & & \multicolumn{3}{|c|}{$\begin{array}{l}\text { Sample PFS* } \\
\text { OS* }\end{array}$} & \multicolumn{3}{|c|}{$\begin{array}{l}\text { Sample PFS* } \\
\text { OS* }\end{array}$} & & \\
\hline Fujitani et al ${ }^{16}$ & 2016 & Asian & MI & 175 & 89 & - & 14.3 & 86 & - & 16.6 & $1.09(0.78-I .52)$ & $\mathrm{I} .0 \mathrm{I}(0.74-\mathrm{I} .37)$ \\
\hline Yuan et al $\left.\right|^{19}$ & 2017 & Asian & $\mathrm{MI} / \mathrm{PI}$ & 201 & 33 & - & 23.6 & 168 & - & 13.8 & $0.67(0.4 \mid-1.09)$ & - \\
\hline Dong et $\mathrm{a}^{20}$ & 2016 & Asian & $\mathrm{MI} / \mathrm{PI}$ & 47 & 29 & - & 23 & 18 & - & 12 & $0.22(0.10-0.50)$ & - \\
\hline Liu et $\mathrm{a}^{24}$ & 2015 & Asian & $\mathrm{MI} / \mathrm{HI}$ & 107 & 32 & 5 & 14 & 75 & 3 & 8 & $0.46(0.3 \mathrm{I}-0.68)$ & $0.45(0.29-0.70)$ \\
\hline Shin et $\mathrm{al}^{23}$ & 2015 & Asian & MI & 101 & 76 & - & 26 & 25 & - & 11 & $0.37(0.20-0.67)$ & - \\
\hline Li et $\mathrm{al}^{21}$ & 2015 & Asian & $\mathrm{MI} / \mathrm{HI}$ & 49 & 25 & 10.9 & 20.5 & 24 & 5 & 9.1 & $0.47(0.23-0.94)$ & $0.45(0.22-0.92)$ \\
\hline Musettini et al ${ }^{18}$ & 2015 & Caucasian & $M I \pm M 0$ & 148 & 62 & - & 10.4 & 86 & - & 10.7 & $1.13(0.78-1.63)$ & - \\
\hline Du et $\mathrm{a}^{25}$ & 2014 & Asian & $M I \pm M 0$ & 72 & 50 & - & 30.2 & 22 & - & 8.9 & $0.29(0.14-0.97)$ & - \\
\hline Yang et $\mathrm{a}^{22}$ & 2015 & Asian & $\mathrm{MI} / \mathrm{PI}$ & 154 & 71 & - & 18.37 & 83 & - & 11.77 & $0.47(0.34-0.66)$ & - \\
\hline $\mathrm{He}$ et $\mathrm{al}^{7}$ & 2013 & Asian & $M I \pm M 0$ & 737 & $4 \mid 4$ & - & 28 & 323 & - & 10.37 & $0.31(0.25-0.38)$ & - \\
\hline Yamamoto et $\mathrm{a}^{26}$ & 2013 & Asian & Mo & 34 & 20 & - & 24.9 & 14 & - & 15.9 & $0.46(0.13-1.59)$ & - \\
\hline Sougioultzis et al ${ }^{17}$ & 2011 & Caucasian & $M I \pm M 0$ & 311 & 218 & - & 12.37 & 93 & - & 3.73 & $0.083(0.06-0.13)$ & - \\
\hline Kim et $\mathrm{al}^{27}$ & 2011 & Asian & $M I \pm M 0$ & 274 & 89 & - & 15.5 & 185 & - & 9 & $0.65(0.45-0.94)$ & - \\
\hline
\end{tabular}

Notes: *median.

Abbreviations: PFS, median progression-free survival (month); OS, median overall survival (month); PI, peritoneal metastasis; HI, liver metastasis.

Table 2 Quality assessment of trials included in the present study

\begin{tabular}{|c|c|c|c|c|c|c|c|c|}
\hline Study & Year & Randomization & $\begin{array}{l}\text { Allocation } \\
\text { concealment }\end{array}$ & $\begin{array}{l}\text { Homogeneous } \\
\text { baseline } \\
\text { characteristic }\end{array}$ & $\begin{array}{l}\text { Eligibility } \\
\text { criteria }\end{array}$ & $\begin{array}{l}\text { Loss to } \\
\text { follow-up } \\
\text { and dropout } \\
\text { described }\end{array}$ & $\begin{array}{l}\text { Intention- } \\
\text { to-treat } \\
\text { analysis }\end{array}$ & $\begin{array}{l}\text { Study } \\
\text { quality }\end{array}$ \\
\hline Fujitani et al ${ }^{16}$ & 2016 & Yes & No & Yes & Yes & Yes & Yes & Fair \\
\hline \multirow[t]{2}{*}{ Author } & Year & $\begin{array}{l}\text { Newcastle-Ottawa } \\
\text { Scale }\end{array}$ & & & & & & \\
\hline & & \multicolumn{4}{|l|}{ Selection } & Comparability & Outcome & \\
\hline Yuan et al ${ }^{19}$ & 2017 & $\star \star \star \star え$ & & & & $\star \star$ & $\star \star \star \Sigma$ & \\
\hline Dong et $\mathrm{a}^{20}$ & 2016 & 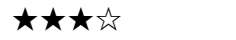 & & & & 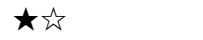 & 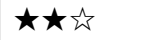 & \\
\hline Liu et $\mathrm{a}^{24}$ & 2015 & $\star \star \star \star え$ & & & & $\star \star \Delta$ & $\star \star \star \Delta 力$ & \\
\hline Yang et $\mathrm{a}^{22}$ & 2015 & 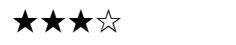 & & & & $\star \star \Delta$ & $\star \star \star \hbar 勺$ & \\
\hline Shin et $\mathrm{al}^{23}$ & 2015 & $\star \star \star \star え 々$ & & & & 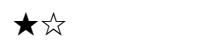 & $\star \star \star 认$ & \\
\hline Musettini et al ${ }^{18}$ & 2015 & 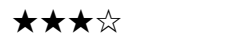 & & & & 论㑔 & 太市公 & \\
\hline Li et $\mathrm{al}^{21}$ & 2015 & $\star \star \star \star え$ & & & & 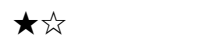 & 大论猔 & \\
\hline Du et $\mathrm{al}^{25}$ & 2014 & 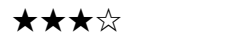 & & & & 论㑔 & $\star \star \star \hbar$ & \\
\hline He et $\mathrm{al}^{7}$ & 2013 & 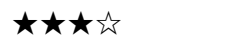 & & & & 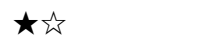 & $\star \star \star \Delta$ & \\
\hline Yamamoto et $\mathrm{a}^{26}$ & 2013 & 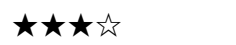 & & & & 必记 & $\star \star \star 々$ & \\
\hline Sougioultzis et $\mathrm{al}^{17}$ & 2011 & 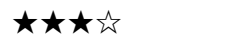 & & & & $\star \star$ & $\star \star \star \Delta 了$ & \\
\hline Kim et $\mathrm{al}^{27}$ & 2011 & 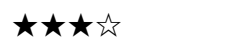 & & & & $\star \star$ & $\star \star \star 々$ & \\
\hline
\end{tabular}

Notes: $\star$ indicates high quality for each choice among the selection, comparability, and outcome items; is indicates that it does not meet the high quality standards for each choice among the selection, comparability, and outcome items. 
where palliative gastrectomy plus chemotherapy reduced the risk of death by $57 \%$ compared with chemotherapy alone. Data could be obtained for PFS from one RCT and two cohort studies. As shown in Figure 3, the pooled HR for PFS was $0.61(95 \% \mathrm{CI}=0.33-1.13, P=0.110)$ and the difference was not statistically significant. However, the combined HR for two cohort studies was $0.45(95 \% \mathrm{CI}=0.31-0.66, P<0.001)$ and the difference was significant, where palliative gastrectomy combined with chemotherapy obtained an overall reduction of $55 \%$ in disease progression.

\section{Subgroup and sensitivity analyses}

When we assessed the heterogeneity for the 13 selected trials, the $I^{2}$ statistic was $91 \%$, thereby indicating a high amount of heterogeneity between the studies. In order to identify the source of heterogeneity, we first conducted sensitivity analysis, and we found that the significant heterogeneity mainly came from three trials: Fujitani et al, ${ }^{16}$ Musettini et al, ${ }^{18}$ and Sougioultzis et al. ${ }^{17}$ After further exploration, we determined that the study by Fujitani et al ${ }^{16}$ was an RCT, whereas the others were cohort studies, where the race was Caucasian in Musettini et al ${ }^{18}$ and Sougioultzis et al, ${ }^{17}$ which differed from the other trials.

Subgroup analysis was then performed for these 13 trials based on the races of the patients, study type, $M$ stage, and site of distant metastasis to determine the sources of heterogeneity and to reduce the heterogeneity but also to identify whether palliative surgery plus chemotherapy was

\begin{tabular}{|c|c|c|c|c|c|c|c|}
\hline Study or subgroup & log [Hazard ratio] & SE & Weight & $\begin{array}{c}\text { Hazard ratio } \\
\mathrm{IV} \text {, random, } 95 \% \mathrm{Cl}\end{array}$ & \multicolumn{3}{|c|}{$\begin{array}{c}\text { Hazard ratio } \\
\mathrm{IV} \text {, random, } 95 \% \mathrm{Cl}\end{array}$} \\
\hline Dong2016 & -1.5 & 0.42 & $6.6 \%$ & $0.22[0.10,0.51]$ & & & \\
\hline Du2014 & -1.23 & 0.42 & $6.6 \%$ & $0.29[0.13,0.67]$ & & & \\
\hline Fujitani2016 & 0.09 & 0.17 & $8.5 \%$ & $1.09[0.78,1.53]$ & & & \\
\hline He2013 & -1.17 & 0.11 & $8.8 \%$ & $0.31[0.25,0.39]$ & & & \\
\hline Kim2011 & -0.43 & 0.19 & $8.4 \%$ & $0.65[0.45,0.94]$ & & & \\
\hline Li2015 & -0.76 & 0.35 & $7.2 \%$ & $0.47[0.24,0.93]$ & & & \\
\hline Liu2015 & -0.78 & 0.2 & $8.3 \%$ & $0.46[0.31,0.68]$ & & & \\
\hline Musettini2015 & 0.12 & 0.19 & $8.4 \%$ & $1.13[0.78,1.64]$ & & & \\
\hline Shin2015 & -1 & 0.31 & $7.5 \%$ & $0.37[0.20,0.68]$ & & & \\
\hline sougioultzis2011 & -2.49 & 0.21 & $8.3 \%$ & $0.08[0.05,0.13]$ & $\rightarrow$ & & \\
\hline Yamamoto2013 & -0.77 & 0.63 & $4.9 \%$ & $0.46[0.13,1.59]$ & & - & \\
\hline Yang2013 & -0.75 & 0.17 & $8.5 \%$ & $0.47[0.34,0.66]$ & & & \\
\hline Yuan2017 & -0.4 & 0.25 & $8.0 \%$ & $0.67[0.41,1.09]$ & & & \\
\hline Total $(95 \% \mathrm{Cl})$ & & & $100.0 \%$ & $0.43[0.29,0.65]$ & & & \\
\hline $\begin{array}{l}\text { Heterogeneity: } \tau^{2}= \\
\text { Test for overall effe }\end{array}$ & $\begin{array}{l}; \chi^{2}=137.63, d f=12 \\
z=4.02(P<0.0001)\end{array}$ & ) & $.00001)$ & $91 \%$ & $\begin{array}{l}0.1 \\
\text { Favors } S \text { and } C\end{array}$ & ${ }^{1}$ Favors $\mathrm{C}^{10}$ & 100 \\
\hline
\end{tabular}

Figure 2 HR for overall survival

Notes: $\mathrm{S}$ and $\mathrm{C}$ : palliative gastrectomy and chemotherapy; C: chemotherapy alone.

Abbreviation: SE, standard error.

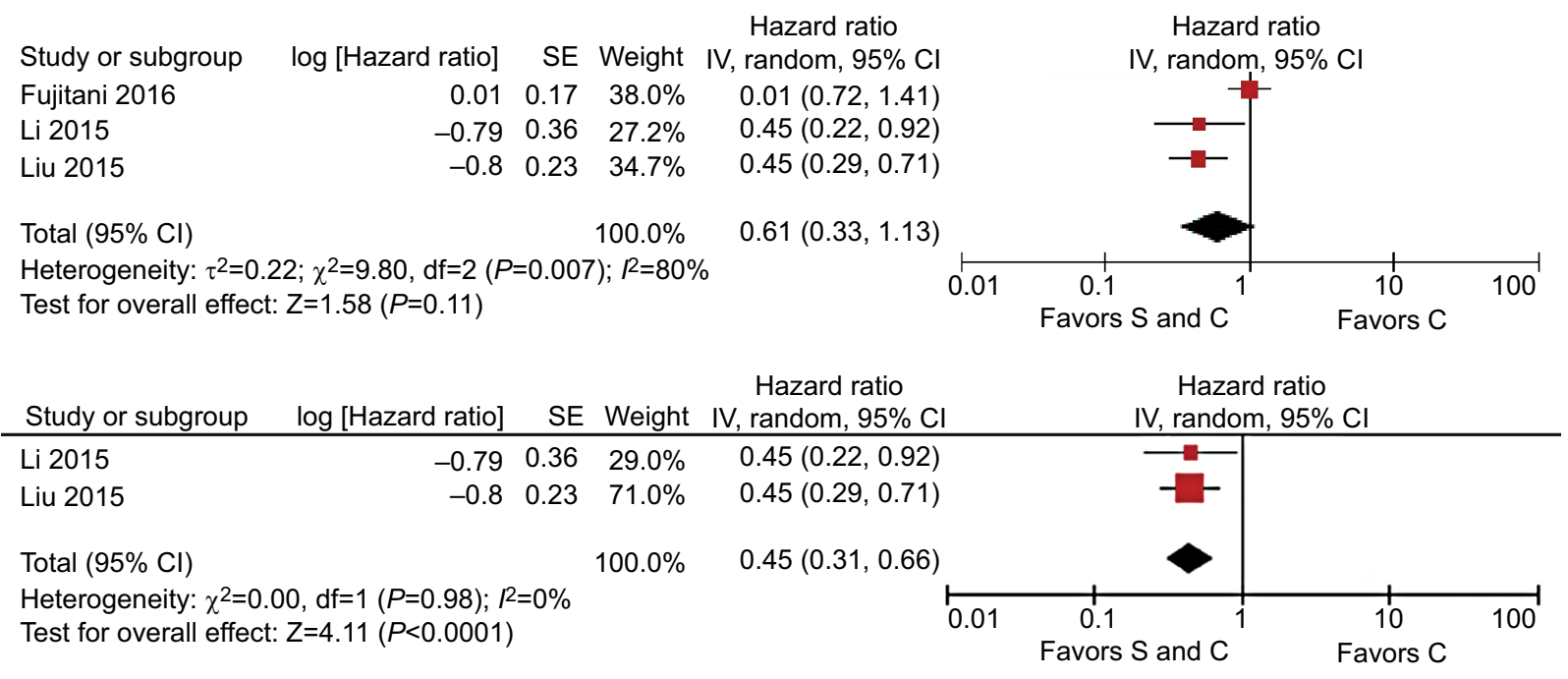

Figure 3 HR for progression-free survival

Notes: S and C: palliative gastrectomy and chemotherapy; C: chemotherapy alone.

Abbreviation: SE, standard error. 
superior to chemotherapy alone in different respects. The overall HR for OS in all the cohort studies was $0.40(95 \%$ $\mathrm{CI}=0.27-0.60, P<0.001, I^{2}=90 \%$, Figure 4$)$. The overall HR for OS among Caucasians was 0.31 (95\% $\mathrm{CI}=0.02-3.95$, $P=0.360, I^{2}=91 \%$ ) and the HR for OS among Asians was $0.47\left(95 \% \mathrm{CI}=0.35-0.64, P<0.001, I^{2}=80 \%\right)$, but significant heterogeneity was not identified between the race subgroups $\left(P=0.74, I^{2}=0 \%\right.$, Figure 5$)$. In addition to the Caucasian race subgroup $(P=0.360)$, the other subgroups all supported the superior performance of surgery plus chemotherapy compared with chemotherapy alone.

We analyzed the $M$ stage gastric cancer subgroups for OS, where the pooled HR for the M1 stage subgroup was $0.53\left(95 \% \mathrm{CI}=0.40-0.72, P<0.001, I^{2}=68 \%\right)$ and the pooled HR for the M0 \pm M1 stage subgroup was $0.30(95 \%$ $\left.\mathrm{CI}=0.11-0.85, P=0.020, I^{2}=96 \%\right)$, and thus heterogeneity was identified between the $\mathrm{M}$ stage subgroups $\left(P=0.300, I^{2}=6 \%\right.$, Figure 6). The heterogeneity was reduced by using the $M$ stage subgroups, but $I^{2}$ exceeded $50 \%$ and the heterogeneity was still significant. Therefore, we excluded the studies ${ }^{16-18}$ that caused significant heterogeneity according to sensitivity analysis. Finally, we included the cohort studies with Asians to produce an M stage subgroup. For OS, the pooled HR for the M1 stage subgroup was $0.49(95 \% \mathrm{CI}=0.41-0.60$, $P<0.001, I^{2}=16 \%$ ) and the pooled HR for the M0 \pm M1 stage subgroup was $0.31\left(95 \% \mathrm{CI}=0.25-0.38, P<0.001, I^{2}=0 \%\right)$, and thus significant heterogeneity was identified between the $\mathrm{M}$ stage subgroups $\left(P=0.001, I^{2}=90.3 \%\right.$, Figure 7$)$. In summary, the $M$ stages were also a source of heterogeneity and palliative gastrectomy plus chemotherapy was superior to chemotherapy alone for M1 stage gastric cancer.

Five studies of M1 stage gastric cancer reported the actual sites of metastasis. Three trials ${ }^{19,20,22}$ described patients with peritoneal dissemination and two trials ${ }^{21,24}$ described patients with liver metastasis. For OS, the pooled HR for peritoneal dissemination was $0.46(95 \% \mathrm{CI}=0.28-0.73, P=0.001$, $I^{2}=61 \%$, Figure 8 ) and the pooled HR for liver metastasis was $0.46\left(95 \% \mathrm{CI}=0.33-0.65, P<0.001, I^{2}=0 \%\right.$, Figure 9$)$. For both peritoneal metastasis and hepatic metastases, it was shown that surgery plus chemotherapy was more beneficial than chemotherapy alone.

\section{Publication bias}

According to assessments based on Egger's test $(P=0.969)$ and Beggar's test $(P=0.141)$, there was no significant publication bias in the articles included in this meta-analysis. The

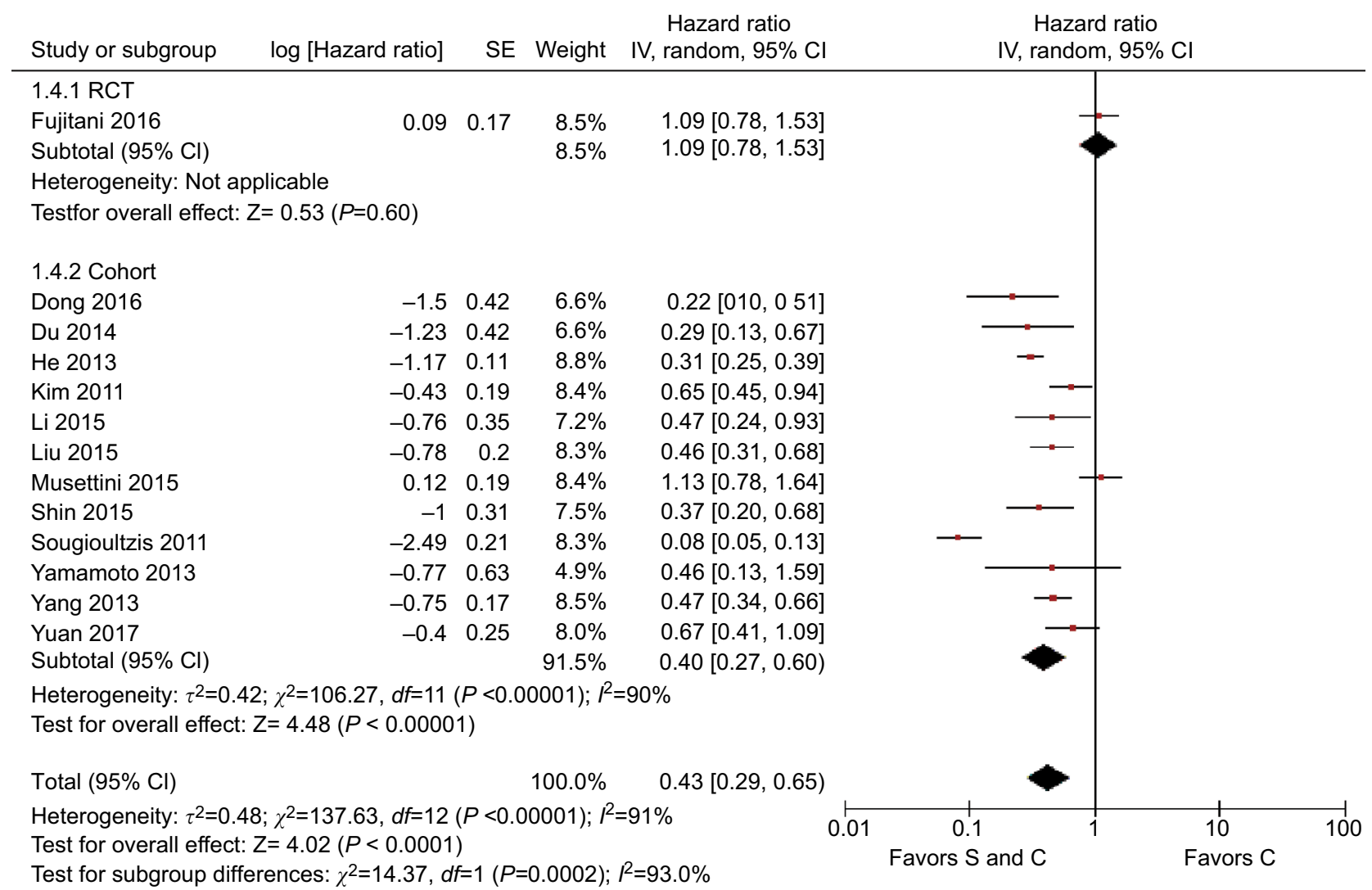

Figure 4 HR for different study

Notes: S and C: palliative gastrectomy and chemotherapy; C: chemotherapy alone.

Abbreviation: SE, standard error. 


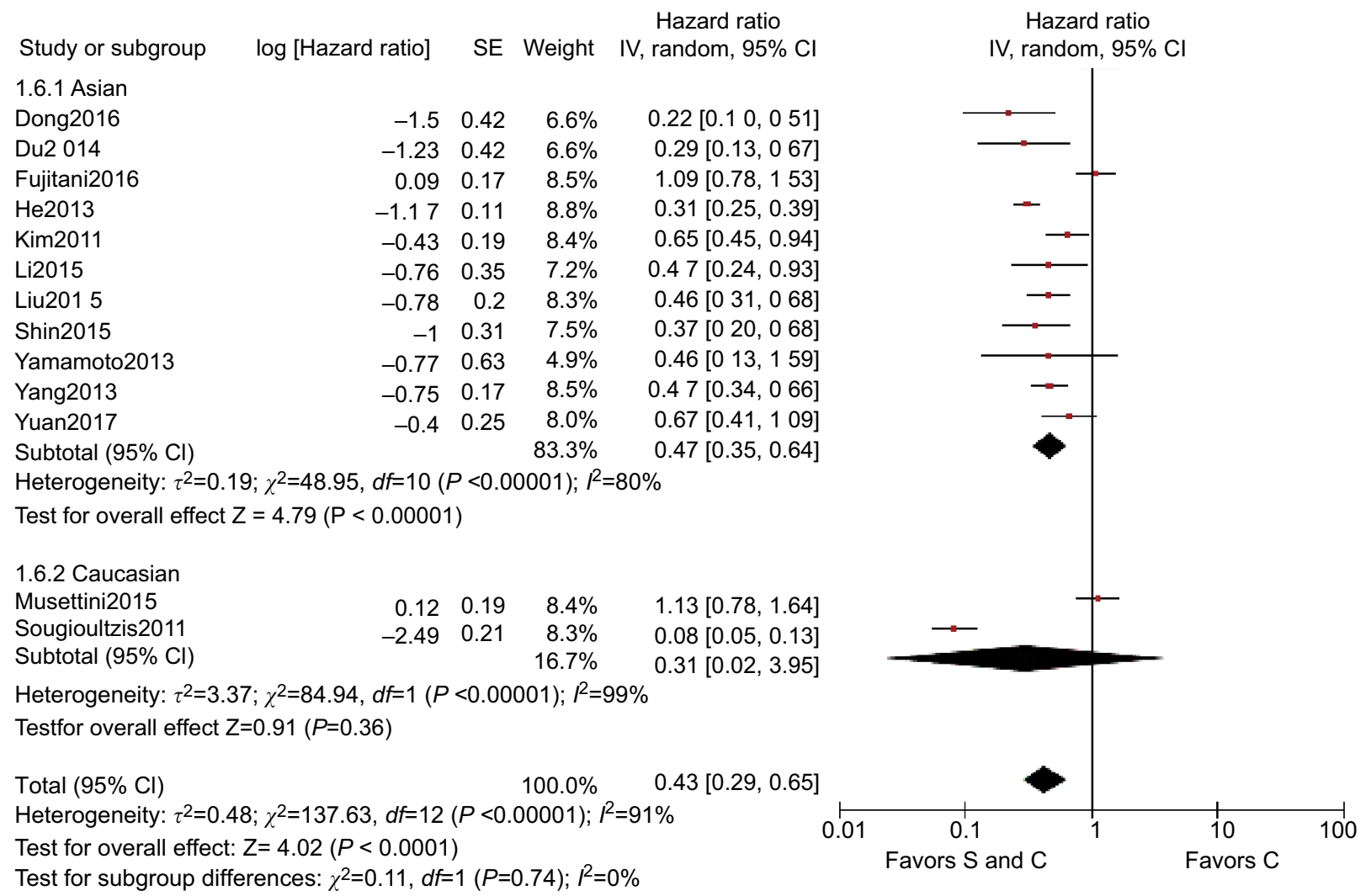

Figure 5 HR for different race

Notes: $\mathrm{S}$ and $\mathrm{C}$ : palliative gastrectomy and chemotherapy; C: chemotherapy alone.

Abbreviation: SE, standard error.

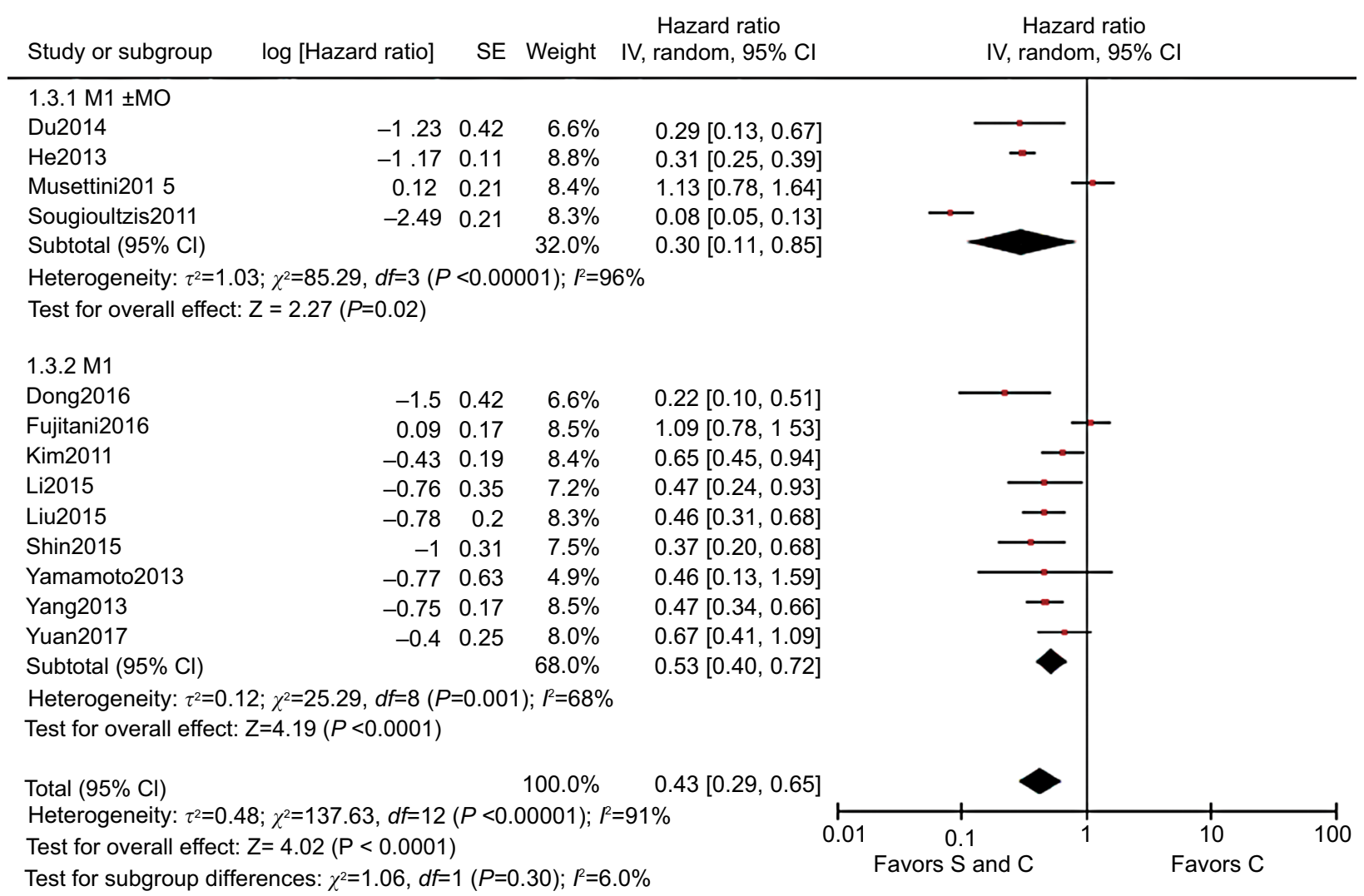

Figure 6 HR for M stage of all study

Notes: S and C: palliative gastrectomy and chemotherapy; C: chemotherapy alone.

Abbreviation: SE, standard error. 


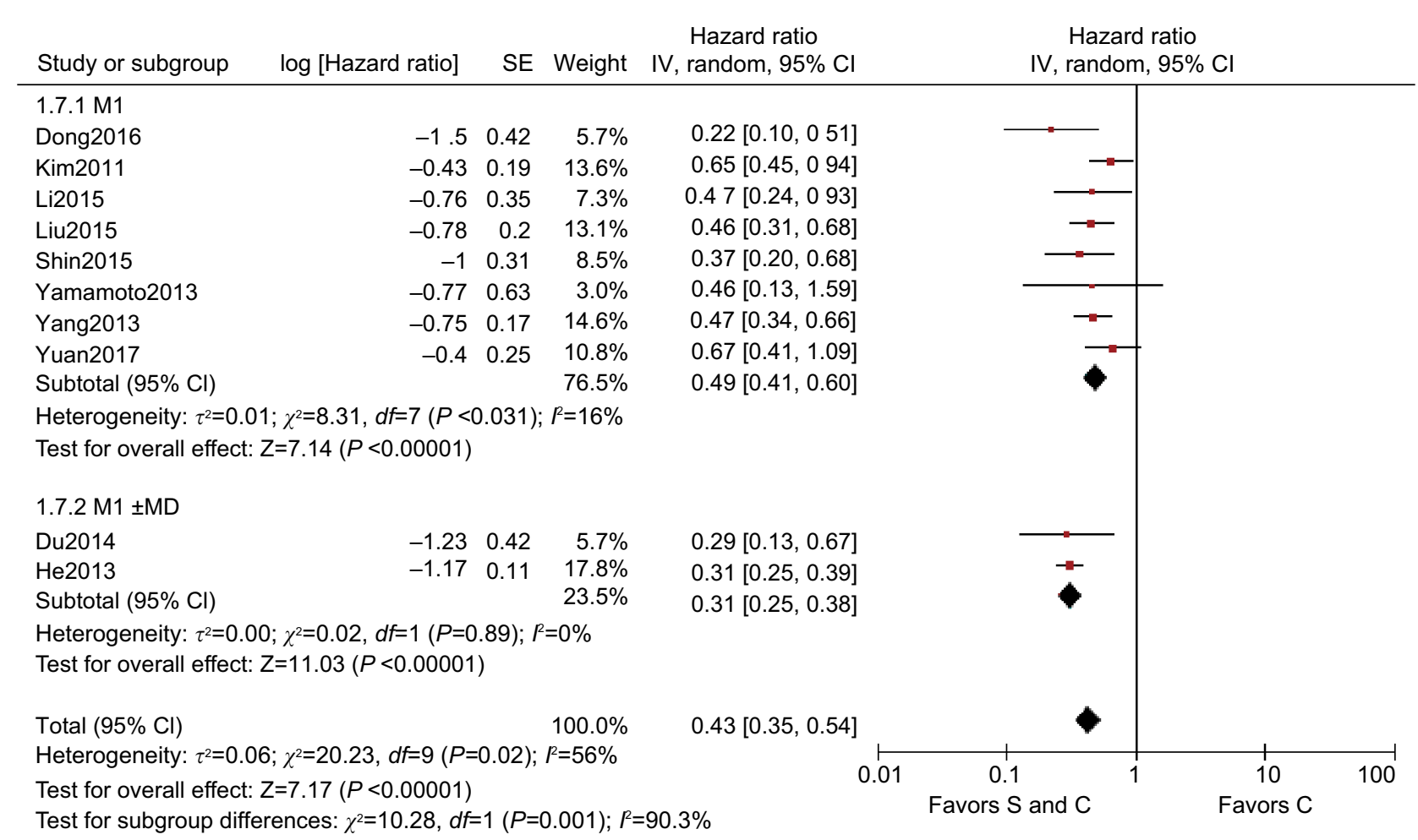

Figure 7 HR for subgroup $M$ stage of all cohort study in Asian

Notes: $S$ and C: palliative gastrectomy and chemotherapy; C: chemotherapy alone.

Abbreviation: SE, standard error.

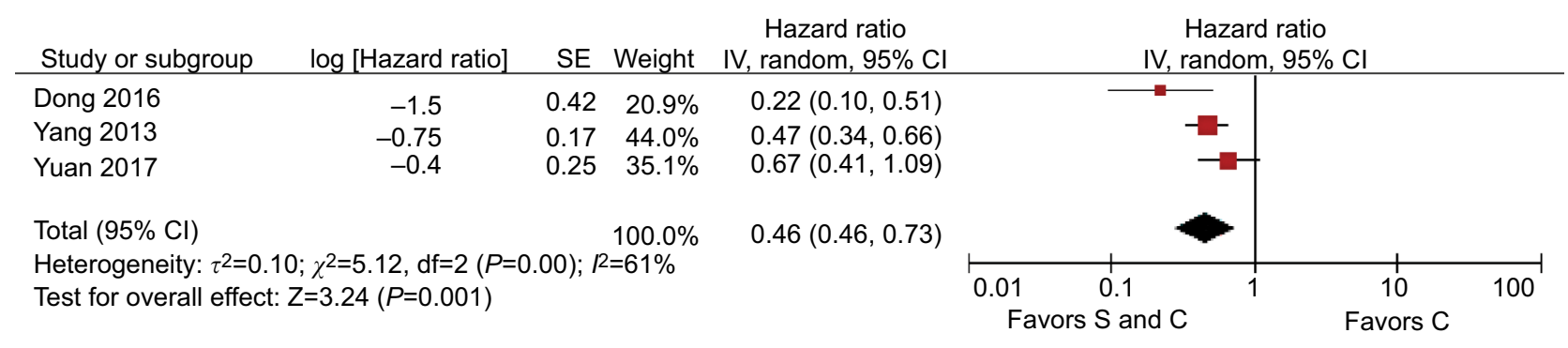

Figure 8 HR for peritoneal dissemination

Notes: $\mathrm{S}$ and C: palliative gastrectomy and chemotherapy; C: chemotherapy alone.

Abbreviation: SE, standard error.

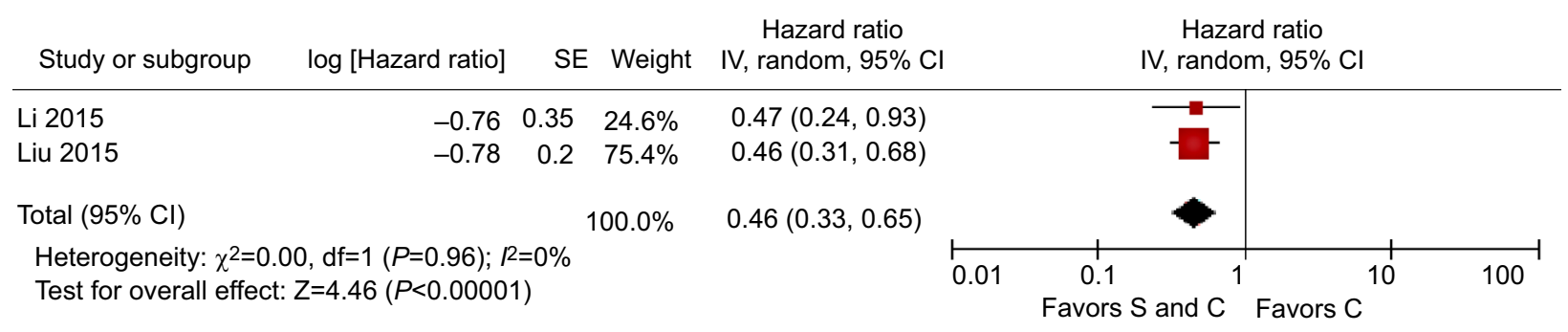

Figure 9 HR for liver metastasis

Notes: S and C: palliative gastrectomy and chemotherapy; C: chemotherapy alone.

Abbreviation: SE, standard error.

funnel diagrams with insignificant asymmetry are shown in Figure 10.

\section{Discussion}

Gastric cancer is a disease with a very poor prognosis. In China, $\sim 38.5 \%-59 \%$ patients with gastric cancer have reached stage IV when their diagnosis is first confirmed. ${ }^{28-30}$ Due to recent advances in chemotherapy regimens, the survival rate has increased for incurable gastric cancer patients, but the effect of palliative gastrectomy combined with chemotherapy is still unclear. ${ }^{31}$ According to the 2009 annual conference of the JGCA, the 5-year OS was $88 \%$ in 


\section{A}

Begg's funnel plot with pseudo $95 \%$ confidence limits

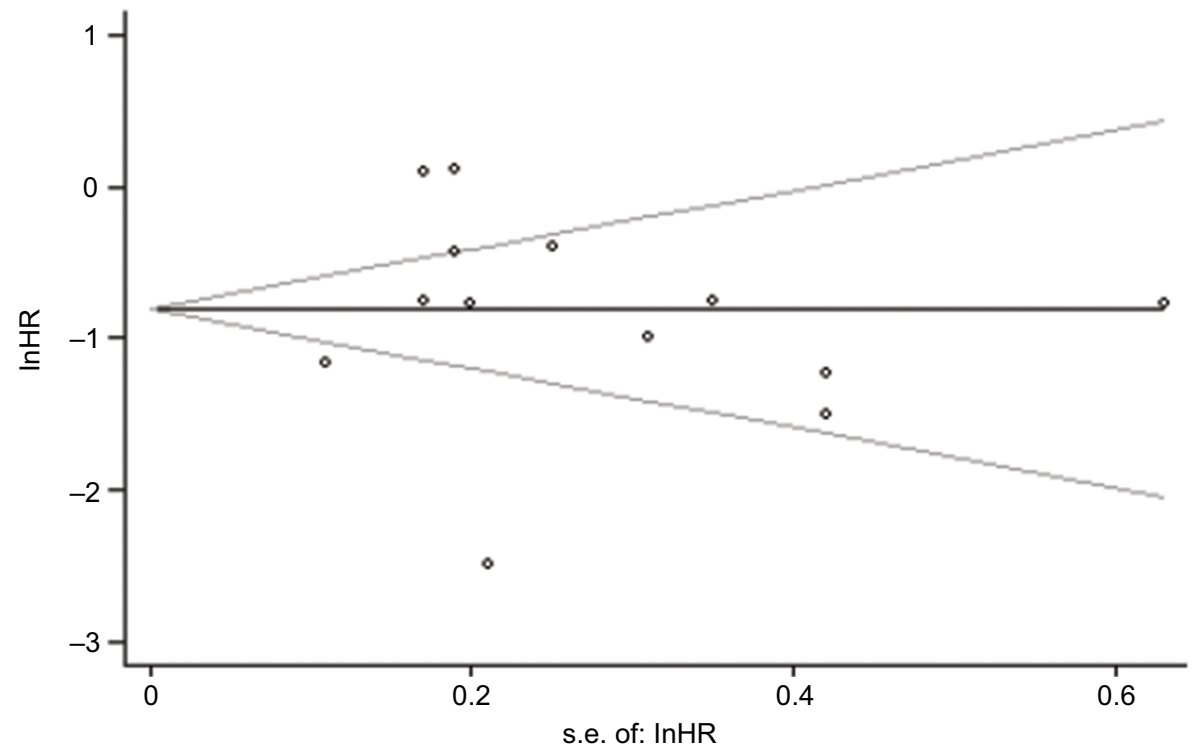

B

Egger's publication bias plot

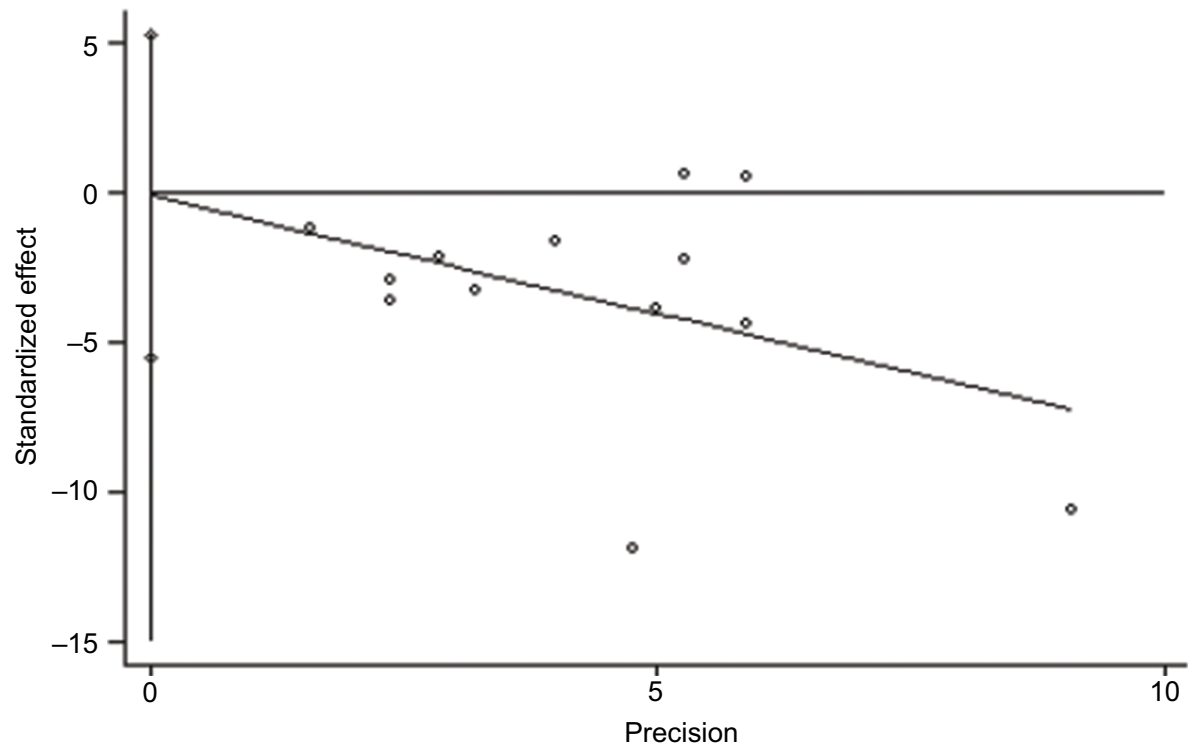

Figure 10 Test for publication bias.

Notes: Based on $(\mathbf{A})$ Begger's test $(p=0.14 I)$ and $(\mathbf{B})$ Egger's test $(p=0.969)$, there was no significant publication bias among the articles included.

resected patients without residual tumors, $1.5 \%$ in unresected patients, and $9.9 \%$ in resected patients with residual tumors, which indicates that palliative gastrectomy could improve the survival of advanced gastric cancer patients and give them a good prognosis. ${ }^{32,33}$ From another perspective, palliative gastrectomy may be beneficial for incurable advanced gastric cancer because it relieves the symptoms of advanced gastric cancer, including obstruction and bleeding, but it also prevents perforation or debilitating ascites to improve the quality of life. In addition, palliative gastrectomy can reduce the tumor burden to improve the response to adjuvant modalities and enhance the immunologic benefit due to the immunosuppressive cytokines produced by the tumor itself. ${ }^{34,35}$ Moreover, the response to chemotherapy is the only independent prognostic factor for patient survival, and adjuvant gastrectomy obtains a reasonable patient response with respect to preoperative chemotherapy. A phase II study conducted by Kang et al evaluated this combination in advanced gastric cancer and obtained promising results, including a high response rate ( $44.5 \%$ partial response) and 
prolonged patient survival (median OS=11.3 months). ${ }^{21,36} \mathrm{~A}$ REGATTA trial comprising an RCT concluded that palliative resection combined with chemotherapy is not superior to chemotherapy alone. ${ }^{16}$ Thus, in order to further optimize the treatment plan, more evidence is urgently needed to support the formulation of relevant treatment plans because the performance of multiple RCTs requires time. Therefore, we performed this meta-analysis. Based on the median survival times of the original articles and the calculated weighted average values, we calculated the median survival times and found that palliative gastrectomy combined chemotherapy could significantly improve the median OS of incurable advanced gastric cancer patients compared with chemotherapy alone (19.65vs 10.70). ${ }^{37}$

This meta-analysis of 13 trials demonstrated a survival benefit of palliative gastrectomy combined with chemotherapy, which agreed with our expectations. Due to the presence of significant heterogeneity, we applied various measures to identify and reduce the heterogeneity, such as sensitivity analysis and subgroup analysis. Interestingly, our interethnic subgroup analysis identified no significant heterogeneity among subgroups under the random effects model $\left(I^{2}=0 \%\right)$, whereas the heterogeneity was significant after using the fixed effects model $\left(I^{2}=73.3 \%\right)$. According to the Cochrane handbook, the differences in these analytical results may have been due to the different sample sizes in the trials, which ranged from 34 to 737 . Using the fixed effects model, the weights of the trials with large sample sizes were greater, whereas the weights given to the studies with large and small sample sizes differed little when using the random effects model. In addition, considerations of clinical significance in the research design may vary among different countries. Our results suggested that race was a source of heterogeneity. ${ }^{38}$ Sun et al found that stage M1 gastric cancer patients could obtain significant survival benefits from palliative gastrectomy. ${ }^{37}$ Thus, we explored whether palliative gastrectomy plus chemotherapy could also be beneficial for stage M1 gastric cancer. At present, the incidence and mortality due to gastric cancer are very high in Asians, ${ }^{38,39}$ so we separated an Asian subgroup that included nine cohort studies. The final subgroup results for the M1 stage also supported palliative gastrectomy plus chemotherapy and the heterogeneity was not significant $(\mathrm{HR}=0.49,95 \% \mathrm{CI}=0.41-0.60$, $\left.P=0.31, I^{2}=16 \%\right)$. Some studies have shown that palliative gastrectomy obtained no survival benefit in patients with peritoneal metastases..$^{32,40-42}$ However, our analysis demonstrated that both peritoneal metastasis ( $\mathrm{HR}=0.46,95 \%$ $\left.\mathrm{CI}=0.28-0.73, I^{2}=61 \%\right)$ and hepatic metastasis $(\mathrm{HR}=0.46$,
95\% CI=0.33-0.65, $I^{2}=0 \%$ ) benefited from palliative gastrectomy combined with chemotherapy.

According to our meta-analysis, surgery and chemotherapy were the two main factors that affected the ultimate survival of gastric cancer patients. Palliative gastrectomy was the treatment factor considered in this meta-analysis. During the treatment of primary tumors, $\mathrm{R} 0$ resection is the best and most effective procedure, where it removes all tumors and microscopic examination detects no tumor cells in the resection margin. ${ }^{43}$ However, some of the patients included in this study failed to achieve $\mathrm{R} 0$ resection. If the rate of $\mathrm{R} 0$ resection was better, then the experimental group may have acquired more survival benefits. D2 lymphadenectomy may increase postoperative complication, but it is still considered a more effective approach for advanced gastric cancer. ${ }^{44-49}$ Galizia et al found that modified D2 lymphadenectomy (including node stations $1-7,8 \mathrm{a}, 9$, and $11 \mathrm{p}$, but excluding node stations $10,11 \mathrm{~d}$, and 12a) did not increase postoperative complications compared with lymphadenectomy, and it also achieved the same effect as standard D2 lymphadenectomy. ${ }^{50}$ Moreover, Kim et al found that gastrectomy combined with metastasectomy could achieve a good survival outcome. ${ }^{27}$ In addition, if the surgery achieves R0 resection, then gastrectomy combined with metastasectomy can yield higher survival rates. ${ }^{51,52}$ Chemotherapy is another important factor that affects the survival of patients with advanced gastric cancer patients. Most of the patients included in this study received first-line chemotherapy. Yuan et al and Nie et al concluded that the period of first-line chemotherapy appears to have an effect on the final OS for advanced gastric cancer patients. ${ }^{19,53}$ In East Asia, neoadjuvant chemotherapy combined with D2 gastrectomy is used widely, but Yang et al found that compared with surgery alone, neoadjuvant chemotherapy alone was not sufficient to improve the OS for gastric cancer patients, although significant survival benefits were obtained with increased PFS and decreased distant metastasis under perioperative chemotherapy. ${ }^{54}$ Moreover, neoadjuvant chemotherapy has been used to downstage the tumor in order to make R0 resection more achievable ${ }^{25}$ In recent years, due to the related survival benefits, hyperthermic intraperitoneal chemotherapy (HIPEC) has been used increasingly for peritoneal metastases in selected indications. ${ }^{55}$ In addition, there are some ongoing RCTs of HIPEC, and a clear trend in HIPEC trial design involves changing from therapeutic toward preventive indications. ${ }^{56}$

In the present study, we found that palliative gastrectomy combined with chemotherapy was more advantageous 
compared with chemotherapy alone in incurable advanced gastric cancer patients, including in different races, but also in peritoneal metastases and hepatic metastases. These results can be used as a reference for clinical work. However, although we concluded that palliative gastrectomy combined with chemotherapy can be beneficial for advanced gastric cancer patients, not every patient with advanced gastric cancer was suitable for receiving surgery because of intolerance due to age, low ECOG (Eastern Cooperative Oncology Group) performance status, multiple organ metastases, and other factors. Identifying the best indications for each type of chemotherapy is still an important goal of future research. Furthermore, our meta-analysis still had some limitations. First, most of the studies included were retrospective, and there was limitation to extract strong conclusions. In addition, we pooled the HRs from studies with different designs, where only the REGATTA RCT with a small sample size and unblinding for treatment assignment had fair quality, ${ }^{8}$ although it was still a source of heterogeneity. Second, the heterogeneity was significant when all the studies were pooled. After sensitivity analysis and subgroup analysis, we identified and reduced some sources of heterogeneity, but heterogeneity was still present in several outcomes and it could not be explained. Finally, several related outcomes could not be evaluated because of the paucity of data, including the period of chemotherapy, neoadjuvant chemotherapy, gastrectomy plus metastasectomy, and R0 resection.

The REGATTA clinical trial was the first RCT to explore whether palliative gastrectomy combined with chemotherapy is more advantageous than chemotherapy alone, and it obtained completely different results compared with most previous studies, but it had some weaknesses. First, due to the absence of blinding, selective bias affected the experimental design for the trial. Second, some studies have concluded that D2 lymphadenectomy is the most effective procedure for advanced gastric cancer, ${ }^{44-50}$ but all the patients in the experimental group received D1 lymphadenectomy, which may explain the slightly low survival benefit. Finally, the number of cycles of palliative gastrectomy combined with chemotherapy was less than that of chemotherapy alone, and thus the experimental group may have benefited less from chemotherapy. To further understand whether palliative gastrectomy combined with chemotherapy can benefit advanced gastric cancer patients, more RCTs with a larger patient cohort and the same tumor response should be investigated. If the concept proves effective, then this could potentially lead to a new standard of care with direct benefits for cancer patients with incurable factors. ${ }^{57}$

\section{Conclusion}

Further research is still needed, but the results of our metaanalysis suggest that palliative gastrectomy plus chemotherapy is superior to chemotherapy alone in incurable advanced gastric cancer patients. Moreover, palliative gastrectomy plus chemotherapy may improve OS of the gastric cancer patients with synchronous peritoneal metastases or hepatic metastases.

\section{Author contributions}

PLW and BM designed the research. PW and ZZ undertook the literature search. SY, WH, and YT analyzed the data and interpreted the results. PW wrote the paper. $\mathrm{ZZ}, \mathrm{ZW}$, and $\mathrm{HX}$ revised the paper. All authors contributed toward data analysis, drafting and critically revising the paper and agree to be accountable for all aspects of the work.

\section{Disclosure}

The authors report no conflicts of interest in this work.

\section{References}

1. Wagner AD, Syn NL, Moehler M, et al. Chemotherapy for advanced gastric cancer. Cochrane Database Syst Rev. 2017;8:Cd004064.

2. Thrumurthy SG, Chaudry MA, Chau I, Allum W. Does surgery have a role in managing incurable gastric cancer? Nat Rev Clin Oncol. 2015;12(11):676-682.

3. Schlansky B, Sonnenberg A. Epidemiology of noncardia gastric adenocarcinoma in the United States. Am J Gastroenterol. 2011;106(11):1978-1985.

4. Ajani JA, Bentrem DJ; National Comprehensive Cancer Network. Gastric cancer, version 2.2013: featured updates to the NCCN Guidelines. J Natl Compr Canc Netw. 2013;11(5):531-546.

5. Japanese GCA, Japanese Gastric Cancer Association. Japanese gastric cancer treatment guidelines 2010 (ver. 3). Gastric Cancer. 2011; 14(2):113-123.

6. Japanese Gastric Cancer Association. Japanese Classification of Gastric Carcinoma - 2nd English Edition. Gastric Cancer. 1998;1(1):10-24.

7. He MM, Zhang DS, Wang F, et al. The role of non-curative surgery in incurable, asymptomatic advanced gastric cancer. PLoS One. 2013;8(12):e83921.

8. Shrier I, Boivin JF, Steele RJ, et al. Should meta-analyses of interventions include observational studies in addition to randomized controlled trials? A critical examination of underlying principles. Am J Epidemiol. 2007;166(10):1203-1209.

9. Sobin L, Gospodarowicz M, Wittekind C. International Union Against Cancer (UICC) TNM Classification of Malignant Tumours. 7th ed. New York: Wiley-Liss; 2010:117-126.

10. Sobin L, Wittekind C. International Union Against Cancer (UICC) TNM Classification of Malignant Tumours. 6th ed. New York: Wiley-Liss; 2002:99-106.

11. Japanese Gastric Cancer Association. Japanese gastric cancer treatment guidelines 2014 (ver. 4). Gastric Cancer. 2017;20(1):1-19.

12. Coccolini F, Cotte $\mathrm{E}$, Glehen $\mathrm{O}$, et al. Intraperitoneal chemotherapy in advanced gastric cancer. Meta-analysis of randomized trials. Eur J Surg Oncol. 2014;40(1):12-26.

13. Jia X, Wang R, Zhang C, Cui M, Xu D. Long-term outcomes of total parathyroidectomy with or without autoimplantation for hyperparathyroidism in chronic kidney disease: a meta-analysis. Ther Apher Dial. 2015;19(5):477-485.

14. Tierney JF, Stewart LA, Ghersi D, Burdett S, Sydes MR. Practical methods for incorporating summary time-to-event data into meta-analysis. Trials. 2007;8(1):16. 
15. Haider BA, Olofin I, Wang M, Spiegelman D, Ezzati M, Fawzi WW; Nutrition Impact Model Study Group (anaemia). Anaemia, prenatal iron use, and risk of adverse pregnancy outcomes: systematic review and meta-analysis. BMJ. 2013;346:f3443.

16. Fujitani K, Yang HK; REGATTA Study Investigators. Gastrectomy plus chemotherapy versus chemotherapy alone for advanced gastric cancer with a single non-curable factor (REGATTA): a phase 3, randomised controlled trial. Lancet Oncol. 2016;17(3):309-318.

17. Sougioultzis S, Syrios J, Xynos ID, et al. Palliative gastrectomy and other factors affecting overall survival in stage IV gastric adenocarcinoma patients receiving chemotherapy: a retrospective analysis. Eur J Surg Oncol. 2011;37(4):312-318.

18. Musettini G, Caparello C, Vivaldi C, et al. L29 Palliative gastrectomy in asymptomatic metastatic esophagogastric cancer (EGC): does it make sense? Ann Oncol. 2015;26(Suppl 6):vi.106-vi.

19. Yuan SQ, Nie RC, Chen S, et al. Selective gastric cancer patients with peritoneal seeding benefit from gastrectomy after palliative chemotherapy: a propensity score matching analysis. $J$ Cancer. 2017;8(12):2231-2237.

20. Dong Y, Ma S, Yang S, Luo F, Wang Z, Guo F. Non-curative surgery for patients with gastric cancer with local peritoneal metastasis: a retrospective cohort study. Medicine. 2016;95(49):e5607.

21. Li Z, Fan B, Shan F, et al. Gastrectomy in comprehensive treatment of advanced gastric cancer with synchronous liver metastasis: a prospectively comparative study. World J Surg Oncol. 2015;13:212.

22. Yang K, Liu K, Zhang WH, et al. The value of palliative gastrectomy for gastric cancer patients with intraoperatively proven peritoneal seeding. Medicine. 2015;94(27):e1051.

23. Shin HB, Lee SH, Son YG, Ryu SW, Sohn SS. Chemoresponse after non-curative gastrectomy for M1 gastric cancer. World J Surg Oncol. 2015;13:13.

24. Liu SF, Lu CR, Cheng HD, et al. Comparison of therapeutic efficacy between gastrectomy with transarterial chemoembolization plus systemic chemotherapy and systemic chemotherapy alone in gastric cancer with synchronous liver metastasis. Chin Med J. 2015;128(16):2194-2201.

25. Du Y, Cheng X, Yu P, et al. PCF chemotherapy combined with surgical treatment of late gastric cancer. Hepatogastroenterology. 2014;61(132): 1159-1164.

26. Yamamoto M, Sakaguchi Y, Matsuyama A, Yoshinaga K, Tsutsui S, Ishida T. Surgery after preoperative chemotherapy for patients with unresectable advanced gastric cancer. Oncology. 2013;85(4):241-247.

27. Kim KH, Lee KW, Baek SK, et al. Survival benefit of gastrectomy \pm metastasectomy in patients with metastatic gastric cancer receiving chemotherapy. Gastric Cancer. 2011;14(2):130-138.

28. Wu CX, Zheng Y, Bao PP, et al. Pattern of changing incidence of gastric cancer and its time trend in Shanghai. J Sur Concepts Pract. 2008; 13:24-29.

29. Pang D, Zhang F, Zhang DE. Probe into the surgical scheme of stage ivgastric cancer-a report of 772 cases. Chin J Clin Oncol. 1999;26:809-811.

30. Crookes PF, Incarbone R, Peters JH, Engle S, Bremner CG, Demeester TR. A selective therapeutic approach to gastric cancer in a large public hospital. Am J Surg. 1995;170(6):602-605.

31. Sarela AI, Yelluri S; Leeds Upper Gastrointestinal Cancer Multidisciplinary Team. Gastric adenocarcinoma with distant metastasis: is gastrectomy necessary? Arch Surg. 2007;142(2):143-149.

32. Ikeguchi M, Miyatani K, Takaya S, et al. Role of surgery in the management for gastric cancer with synchronous distant metastases. Indian $J$ Surg Oncol. 2016;7(1):32-36.

33. Nashimoto A, Akazawa K, Isobe Y, et al. Gastric cancer treated in 2002 in Japan: 2009 annual report of the JGCA nationwide registry. Gastric Cancer. 2013;16(1):1-27.

34. Saidi RF, Remine SG, Dudrick PS, Hanna NN. Is there a role for palliative gastrectomy in patients with stage IV gastric cancer? World $J$ Surg. 2006;30(1):21-27.

35. Pollock RE, Roth JA. Cancer-induced immunosuppression: implications for therapy? Semin Surg Oncol. 1989;5(6):414-419.

36. Kang HJ, Chang HM, Kim TW, et al. A phase II study of paclitaxel and capecitabine as a first-line combination chemotherapy for advanced gastric cancer. Br J Cancer. 2008;98(2):316-322.
37. Sun J, Song Y, Wang Z, et al. Clinical significance of palliative gastrectomy on the survival of patients with incurable advanced gastric cancer: a systematic review and meta-analysis. BMC Cancer. 2013;13(1):577.

38. Sun P, Xiang JB, Chen ZY. Meta-analysis of adjuvant chemotherapy after radical surgery for advanced gastric cancer. Br J Surg. 2009;96(1):26-33.

39. Sugano K. Screening of gastric cancer in Asia. Best Pract Res Clin Gastroenterol. 2015;29(6):895-905.

40. Tokunaga M, Terashima M, Tanizawa Y, et al. Survival benefit of palliative gastrectomy in gastric cancer patients with peritoneal metastasis. World J Surg. 2012;36(11):2637-2643.

41. Chen S, Li YF, Feng XY, Zhou ZW, Yuan XH, Chen YB. Significance of palliative gastrectomy for late-stage gastric cancer patients. J Surg Oncol. 2012;106(7):862-871.

42. Ouchi K, Sugawara T, Ono H, et al. Therapeutic significance of palliative operations for gastric cancer for survival and quality of life. $J$ Surg Oncol. 1998;69(1):41-44.

43. Roukos DH. Current status and future perspectives in gastric cancer management. Cancer Treat Rev. 2000;26(4):243-255.

44. Degiuli M, Sasako M; Italian Gastric Cancer Study Group. Randomized clinical trial comparing survival after D1 or D2 gastrectomy for gastric cancer. Br J Surg. 2014;101(2):23-31.

45. Strong VE, Yoon SS. Extended lymphadenectomy in gastric cancer is debatable. World J Surg. 2013;37(8):1773-1777.

46. Jiang L, Yang KH, Guan QL, Zhao P, Chen Y, Tian JH. Survival and recurrence free benefits with different lymphadenectomy for resectable gastric cancer: a meta-analysis. J Surg Oncol. 2013;107(8):807-814.

47. Ferri L. Extended lymphadenectomy in gastric cancer is crucial. World J Surg. 2013;37(8):1768-1772.

48. Cuschieri A, Weeden S, Fielding J, et al. Patient survival after D1 and D2 resections for gastric cancer: long-term results of the MRC randomized surgical trial. Surgical Co-operative Group. Br J Cancer. 1999;79(9-10): 1522-1530.

49. Bonenkamp JJ, Hermans J; Dutch Gastric Cancer Group. Extended lymph-node dissection for gastric cancer. N Engl J Med. 1999;340(12): 908-914.

50. Galizia G, Lieto E, de Vita F, et al. Modified versus standard D2 lymphadenectomy in total gastrectomy for nonjunctional gastric carcinoma with lymph node metastasis. Surgery. 2015;157(2):285-296.

51. Tokunaga M, Ohyama S, Hiki N, Fukunaga T, Aikou S, Yamaguchi T. Can superextended lymph node dissection be justified for gastric cancer with pathologically positive para-aortic lymph nodes? Ann Surg Oncol. 2010;17(8):2031-2036.

52. Sakamoto Y, Ohyama S, Yamamoto J, et al. Surgical resection of liver metastases of gastric cancer: an analysis of a 17-year experience with 22 patients. Surgery. 2003;133(5):507-511.

53. Nie R-C, Yuan S-Q, Chen X-J, Chen Y-B. 230P Selective gastric cancer patients with peritoneal dissemination benefit from palliative gastrectomy after palliative chemotherapy: results from two high-volume institutions. Ann Oncol. 2016;27(Suppl 9):230.

54. Yang Y, Yin X, Sheng L, Xu S, Dong L, Liu L. Perioperative chemotherapy more of a benefit for overall survival than adjuvant chemotherapy for operable gastric cancer: an updated meta-analysis. Sci Rep. 2015;5:12850.

55. Vassos N, Förtsch T, Aladashvili A, Hohenberger W, Croner RS. Repeated cytoreductive surgery (CRS) with hyperthermic intraperitoneal chemotherapy (HIPEC) in patients with recurrent peritoneal carcinomatosis. World J Surg Oncol. 2016;14(1):42.

56. Eveno C, Pocard M. Randomized controlled trials evaluating cytoreductive surgery (CRS) and hyperthermic intraperitoneal chemotherapy (HIPEC) in prevention and therapy of peritoneal metastasis: a systematic review. Pleura Peritoneum. 2016;1(4):169-182.

57. Al-Batran SE, Goetze TO, Mueller DW, et al. The RENAISSANCE (AIO-FLOT5) trial: effect of chemotherapy alone vs. chemotherapy followed by surgical resection on survival and quality of life in patients with limited-metastatic adenocarcinoma of the stomach or esophagogastric junction: a phase III trial of the German AIO/CAO-V/CAOGI. BMC Cancer. 2017;17(1):893. 
Cancer Management and Research

\section{Publish your work in this journal}

Cancer Management and Research is an international, peer-reviewed open access journal focusing on cancer research and the optimal use of preventative and integrated treatment interventions to achieve improved outcomes, enhanced survival and quality of life for the cancer patient.

The manuscript management system is completely online and includes

Submit your manuscript here: https://www.dovepress.com/cancer-management-and-research-journal

a very quick and fair peer-review system, which is all easy to use. Visit $\mathrm{http}: / / \mathrm{www}$.dovepress.com/testimonials.php to read real quotes from published authors. 